\title{
A produção científica em tempos de coronavírus
}

DOI

http://dx.doi.org/10.11606/ 2179-0892.ra.2020.169306
Laura Moutinho

Universidade de São Paulo | Faculdade de Filosofia, Letras e Ciências

Humanas | Departamento de Antropologia | São Paulo, SP, Brasil

Imoutinho@usp.br| https://orcid.org/0000-0001-6479-2711
Pedro de Niemeyer Cesarino

Universidade de São Paulo | Faculdade de Filosofia, Letras e Ciências Humanas | Departamento de Antropologia | São Paulo, SP, Brasil pedrocesarino@gmail.com | https://orcid.org/0000-0002-4158-7712

Fechamos este número da Revista de Antropologia em meio à pandemia do coronavírus. O trabalho foi finalizado no confinamento: medo, ansiedade, luto, notícias estarrecedoras da Itália, Espanha, Estados Unidos tornaram o mundo menor. Ninguém se sente e nem está seguro. Nas palavras de Denise Pimenta, que realizou seu doutorado em Serra Leoa sobre a epidemia do Ebola (2019): "pandemias dizem mais sobre nós mesmos do que a doença em si"’.

Em meio a esse universo de incertezas, a sociedade brasileira está convivendo com o negacionismo e com uma profunda crise política, na qual tem sido frequente o desrespeito às vidas perdidas e ao luto dos que sobreviveram aos entes amados.

Se Byung-Chul Han (2020), ao refletir sobre a pandemia na Europa, nota o desespero de soberania na ação (inútil) de fechar as fronteiras, no Brasil, o presidente, em desespero similar, conclama a população a ir às ruas e o comércio a abrir. Convivemos diariamente com a falta de compaixão por aqueles a quem tem sido negado até mesmo um gesto de luto.

A produção científica, que neste momento deveria receber ainda mais atenção e recursos, sofre ataques tão inacreditáveis quanto inaceitáveis. Uma vez mais, as ciências humanas padecem com a desqualificação. Definir uma ciência como mais importante que outra é abandonar o pensamento científico, rumo ao obscurantismo. A pandemia do coronavírus exige exaustivamente de profissionais da saúde e seus saberes, mas essa está longe de ser uma crise de base exclusivamente sanitária. A crise política conclama os antropólogos e cientistas sociais a dimensionar os efeitos terríveis dos tempos atuais nas relações sociais, em suas dimensões estruturais e cotidianas. Os cortes no apoio financeiro às ciências nos 
últimos anos mostram os efeitos nefastos da estratégia que tem sido adotada. De positivo, este momento parece estar trazendo uma (re)valorização do SUS e um reforço à manutenção de um sistema público de saúde. Países como os Estados Unidos mostram como a ausência de políticas desse tipo é nefasta.

A pandemia nasceu operando um estigma racializador contra os chineses e seus supostos hábitos alimentares. O processo aterrissa nos países de todos os continentes evidenciando o jogo geopolítico, inclusive do conhecimento. $A$ desigualdade de gênero vem ganhando especial destaque nesse cenário. $A$ ciência realizada pela antropologia aborda não somente esses temas, mas nos conclama também a uma reflexão mais ampla. Aprendemos com aqueles que são diferentes de "nós". Ao produzir um conhecimento que é contraintuitivo, a antropologia nos coloca à frente com aspectos negligenciados pelos números e estatísticas. Os cortes à pesquisa e ao pensamento crítico nas ciências humanas são inaceitáveis. Nós e toda a comunidade científica não iremos acatar essa ordem das coisas. Como destacado pela ABA, SBS, ANPOSC, ABCP, "todas as ciências são humanas" - mesmo nesse cenário de uma política desigual, autoritária e desumana.

Essa é a reflexão que abre o atual número da Revista de Antropologia. Adirley Queirós tinha apenas três anos, a mesma idade da recém-criada cidade-satélite de Ceilândia, quando mudou com sua família para Brasília. Sua obra cinematográfica, objeto do artigo de Marco Antonio Conçalves (2020), intitulado "Blade Runner BR, 2071: sitiando fronteiras entre Ceilândia e Brasília (o cinema de Adirley Queirós)", faz emergir as cidades-satélites como espaços de contestação e crítica a projetos autoritários, tais como aqueles que instituíram Brasília no Brasil Central.

Em "A estratégia anti-entrópica do pensamento de Nhanderu", Ana Ramo (2020) trata das noções de temporalidade e de vida entre pensadores guarani, sobretudo anciãos e pajés, mostrando como tais noções são marcadas pelos processos de florescimento e de renovação.

Samir de Angelo (2020), em "Livros e dabucuris", aborda o impacto do tempo dos livros sobre os povos indígenas do Rio Negro. Por meio de uma análise da coleção Narradores indígenas do Rio Negro, o autor explora as maneiras pelas quais grupos hierárquicos do povo Desana transformam livros em agentes de suas dinâmicas políticas e relações de parentesco.

Também sobre transformações temporais versa o artigo de Renato Sztutman (2020), "Perspectivismo contra o Estado", que trata das consequências políticas do conceito de perspectivismo, formulado por Eduardo Viveiros de Castro e Tania Stolze Lima. Tal abordagem é feita a partir das possibilidades de relação entre o perspectivismo e os desafios contemporâneos relacionados às crises do assim chamado antropoceno. 
Num contexto distinto daquele das terras baixas da América do Sul e suas cosmologias contra o Estado, Hilda Landrove Torres (2020) oferece um intrigante estudo sobre os Maya do período clássico. Ao estudar painéis hieroglíficos da cidade de Yaxchilan, a autora verifica a existência de uma complexa iconografia que não era dedicada exatamente à manutenção do poder político, mas sim à transformação da pessoa e do tempo através da ação ritual.

Voltado para o extrativismo comercial de castanha entre os quilombolas de Alto Trombetas (PA), o artigo de Igor Scaramuzzi (2020) apresenta uma etnografia cuidadosa sobre o conceito local de "entender" implicado nas práticas e reflexões derivadas de longas relações com a floresta.

$\mathrm{O}$ artigo "Intimismo entre humanos e animais em um zoológico na Amazônia", de Flávio da Silveira e Matheus Pereira da Silva (2020), também se dedica ao universo das relações interespecíficas. $O$ trabalho busca refletir sobre as "negociações de sentido" entre tratadores e animais, trazendo mais uma contribuição um fértil campo da antropologia contemporânea.

Francirosy Barbosa e Luana Lima (2020), por contraste, nos oferecem um artigo sobre uma área fundamental, embora ainda pouco explorada pela antropologia brasileira, a saber, aquela das relações de gênero e de espaço público entre mulheres muçulmanas, por meio de uma abordagem comparativa entre casos brasileiros e franceses.

O artigo de Rafael Antunes Almeida (2020), brinda os leitores com uma sensível etnografia da doença (a hanseníase) em uma colônia do Ceará destinada ao seu tratamento. A análise lida com silêncios e uma gestão da memória entre aqueles que não vocalizam a dor, numa era em que se entende que falar, cura. $A$ "recusa narrativa" é o tema do artigo "Na varanda, o silêncio hanseníase, esquecimento e esgotamento narrativo na Colônia de Antônio Diogo".

A entrevista com Ana Loforte, antropóloga, feminista, historiadora, mãe e avó moçambicana leva o leitor para a África Austral. Nascida em Inhambane, Loforte coordena a área de formação da WLSA (Women and Law in Southern Africa Research and Education Trust). No diálogo cuidadoso com a pesquisadora, realizado por Vera Gasparetto e Helder Pires Amâncio (2020), o leitor da Revista de Antropologia poderá refletir sobre a história de Moçambique e suas relações com a África do Sul, o colonialismo, a luta pela independência e seus desafios, e sobre a guerra civil, a fome e a pobreza. Sua trajetória pela antropologia lança luzes sobre aquela que realizamos em nosso país.

Que essas leituras sejam úteis e interessantes nesse difícil momento de quarentena e necessário isolamento físico. \#fiquememcasa! 


\section{REFERÊNCIAS BIBLIOCRÁFICAS}

ALMEIDA, Rafael Antunes. 2020.

Na varanda, o silêncio: hanseníase, esquecimento e esgotamento narrativo na Colônia de Antônio Diogo". Revista de Antropologia 63 (1), 35- 58.

https://doi.org/10.11606/2179-

0892.ra.2020.168624.

ANGELO, Samir Ricardo Figalli de. 2020. "Livros e Dabucuris. Continuidades e transformações nas formas de atualizações de diferenças entre os grupos Desana do Alto Rio Negro". Revista De Antropologia 63 (1), 83-104. https://doi. org/10.11606/2179-0892.ra.2020.169173

GASPARETTO, Vera e AMÂNCIO, Helder Pires. 2020. Ana Loforte: história viva de um legado à Antropologia e aos estudos de gênero em Moçambique. Revista De Antropologia 63 (1), 214-226. https:// orcid.org/0000-0001-6726-2169

GONÇALVES, Marco Antonio. 2020.

"Blade Runner BR, 2071: Sitiando fronteiras entre Ceilândia e Brasília (o cinema de Adirley Queirós)". Revista De Antropologia 63 (1), 12-34. https://doi. org/10.11606/2179-0892.ra.2020.168432.

HAN, Byung Chul. 2020. "O coronavírus de hoje e o mundo de amanhã". Disponível em: https://brasil.elpais.com/ideas/202003-22/o-coronavirus-de-hoje-e-o-mundode-amanha-segundo-o-filosofo-byungchul-han.html Acesso em 01/04/2020.
BARBOSA, Francirosy, e LIMA, Luana. 2020. Empoderamentos Múltiplos de Mulheres Muçulmanas em espaços públicos na França e No Brasil. Revista De Antropologia 63 (1), 59 - 82. https://doi. org/10.11606/2179-0892.ra.2020.168619.

PIMENTA, Denise. 2019. O cuidado perigoso: tramas de afeto e risco na Serra Leoa (A epidemia do ebola contada pelas mulheres, vivas e mortas). São Paulo, tese de doutorado, USP.

RAMO, Ana Maria. 2020. "Nos tempos antigos nhanderu soube qual haveria de ser nosso futuro teko": tempo, troca e transformação entre os Guarani. Revista De Antropologia 63 (1), 105-121. https://doi. org/10.11606/2179-0892.ra.2020.168618

SCARAMUZZI, Igor Alexandre Badolato. 2020 "Modos de orientação na floresta e as formas do entender no extrativismo comercial da castanha entre quilombolas do Alto Trombetas, Oriximiná/PA". Revista De Antropologia 63 (1), 143-163. https://doi. org/10.11606/2179-0892.ra.2020.168623.

SILVEIRA, Flávio da; SILVA, Matheus Pereira da. 2020 "Intimismo entre humanos e animais em um zoológico na Amazônia (Belém - PA)". Revista De Antropologia 63 (1), 164-184. https:// doi.org/10.11606/2179-0892.ra.2020.168620. 
SZTUTMAN, Renato. 2020.

"Perspectivismo contra o Estado - Uma política do conceito em busca de um novo conceito de política". Revista De Antropologia 63 (1), 185-213. https://doi. org/10.11606/2179-0892.ra.2020.169177.
TORRES, Hilda Landrove. 2020 "Reflexivity and Self-Referentiality Image: Yaxchilan Panel VII Hieroglyphic Stairway". Revista De Antropologia 63 (1), o०- ००. https://doi.org/10.11606/21790892.ra.2020.169169

Recebido em 15 de abril de 2020. Aceito em 16 de abril de 2020 . 